\title{
Identification of optimum scopes of environmental factors for snails using spatial analysis techniques in Dongting Lake Region, China
}

Jin-Yi Wu ${ }^{1,2,3}$, Yi-Biao Zhou ${ }^{1,2,3^{*}}$, Lin-Han Li ${ }^{1,2,3}$, Sheng-Bang Zheng ${ }^{1,2,3}$, Song Liang ${ }^{4,5}$, Ashley Coatsworth ${ }^{6}$, Guang-Hui Ren ${ }^{7}$, Xiu-Xia Song ${ }^{1,2,3}$, Zhong He ${ }^{8}$, Bin Cai ${ }^{9}$, Jia-Bian You ${ }^{10}$ and Qing-Wu Jiang ${ }^{1,2,3}$

\begin{abstract}
Background: Owing to the harmfulness and seriousness of Schistosomiasis japonica in China, the control and prevention of S. japonica transmission are imperative. As the unique intermediate host of this disease, Oncomelania hupensis plays an important role in the transmission. It has been reported that the snail population in Qiangliang Lake district, Dongting Lake Region has been naturally declining and is slowly becoming extinct. Considering the changes of environmental factors that may cause this phenomenon, we try to explore the relationship between circumstance elements and snails, and then search for the possible optimum scopes of environmental factors for snails.

Methods: Moisture content of soil, $\mathrm{pH}$, temperature of soil and elevation were collected by corresponding apparatus in the study sites. The LISA statistic and GWR model were used to analyze the association between factors and mean snail density, and the values in high-high clustered areas and low-low clustered areas were extracted to find out the possible optimum ranges of these elements for snails.

Results: A total of 8,589 snail specimens were collected from 397 sampling sites in the study field. Besides the mean snail density, three environmental factors including water content, $\mathrm{pH}$ and temperature had high spatial autocorrelation. The spatial clustering suggested that the possible optimum scopes of moisture content, $\mathrm{pH}$, temperature of the soil and elevation were 58.70 to $68.93 \%, 6.80$ to $7.80,22.73$ to $24.23^{\circ} \mathrm{C}$ and 23.50 to $25.97 \mathrm{~m}$, respectively. Moreover, the GWR model showed that the possible optimum ranges of these four factors were 36.58 to $61.08 \%, 6.541$ to $6.89,24.30$ to $25.70^{\circ} \mathrm{C}$ and 23.50 to $29.44 \mathrm{~m}$, respectively.

Conclusion: The results indicated the association between snails and environmental factors was not linear but U-shaped. Considering the results of two analysis methods, the possible optimum scopes of moisture content, $\mathrm{pH}$, temperature of the soil and elevation were $58.70 \%$ to $68.93 \%, 6.6$ to $7.0,22.73^{\circ} \mathrm{C}$ to $24.23^{\circ} \mathrm{C}$, and $23.5 \mathrm{~m}$ to $26.0 \mathrm{~m}$, respectively. The findings in this research will help in making an effective strategy to control snails and provide a method to analyze other factors.
\end{abstract}

Keywords: Schistosomiasis japonica, Oncomelania hupensis, Environmental factors, Spatial clustering, GWR

\footnotetext{
* Correspondence: z_yibiao@hotmail.com

'Department of Epidemiology, School of Public Health, Fudan University, 138

Yi Xue Yuan Road, Shanghai 200032, China

${ }^{2}$ Key Laboratory of Public Health Safety, Ministry of Education, Fudan

University, 138 Yi Xue Yuan Road, Shanghai 200032, China

Full list of author information is available at the end of the article
} 


\section{Background}

Schistosomiasis, a snail-borne parasitic disease of public health, leads to chronic ill-health, with poverty exacerbating its negative health effects. It affects almost 240 million people worldwide, and more than 700 million people live in endemic areas [1]. Schistosomiasis japonica is the most hazardous disease type of the five kinds of Schistosomiasis, and it is difficult to prevent and treat [2,3]. S. japonica has existed in China for over 2000 years, and 671.3 thousand people were still infected with $S$. japonica until 2006 in seven provinces [4-7].

Oncomelania hupensis, found mostly in marshland and lake areas, is the sole intermediate host of S. japonicum. It is closely associated with the transmission and epidemic of S.japonica. The distribution of snails is consistent with the epidemic area of S. japonica [8,9]. The Three Gorges Dam (TGD) is one of several tremendous engineering projects transforming China's ecology and environmental circumstance. However, the construction of Three Gorges Dam (TGD) and the implementation of the South-toNorth Water Diversion Project (SNWDP) were reported to influence the surrounding ecological environment, which might affect the distribution of snails [10-12]. Interestingly, Oncomelania hupensis has declined naturally in Qiangliang Lake district, Dongting Lake Region since 1990, and snails have not been found in the region since 2000 [13]. The Qiangliang Lake district is located in the northwestern Dongting Lake. The area of this region where snails used to live and breed is about $433.2 \mathrm{~km}^{2}$. Therefore, the question of why and how this phenomenon of natural population decline has occurred is undetermined. The possible optimum scopes of environmental factors for the snails captures our interest, which will help explain what drives this natural population decline.

With the development of spatial techniques, increasingly more public health problems have been analyzed using spatial modeling [12,14-24]. In previous research, experiments and field trials have both been used. Prior analyses of the relationship between snails and environmental factors commonly adopted a global model (i.e. ordinary least square regression model (OLS)), which only offered reliable information without considering the spatial variability. Geographically weighted regression (GWR) model overcame this problem, as it made use of spatial information adequately [18,25-28]. GWR is a new local modeling technique for conducting spatial analysis. This technique allows local as opposed to global models of relationships to be measured and mapped. The function is improved with spatial matrix on the basis of the OLS model. Besides GWR, Local Indicators of Spatial Association (LISA) was also used to analyze the data. LISA allows for the decomposition of global indicators, such as Moran's I, into the contribution of each individual observation. The LISA for each observation gives an indication of the extent of significant spatial clustering of similar values around that observation, and the sum of LISAs for all observations is proportional to a global indicator of spatial association [29]. We utilized these techniques to extract useful information and to identify the possible suitable ranges for snails. This study aimed to explore the possible optimum scopes of environmental factors for snails using spatial analysis techniques (both GWR and LISA) in their natural habitats.

\section{Methods}

\section{Study area}

The study was conducted in a bottomland of Dongting Lake Region. Dongting Lake is located at $28^{\circ} 30^{\prime}-30^{\circ} 20^{\prime} \mathrm{N}$ and $111^{\circ} 40^{\prime}-113^{\circ} 40^{\prime} \mathrm{E}$ in the northeastern part of Hunan Province and covers a water surface area of $2,681 \mathrm{~km}^{2}$. Dongting Lake is the second largest water source in China and plays an important role in regulating water levels in the Yangtze River. S. japonica has been endemic in the Dongting Lake region for centuries, and it has had a devastating effect on the public health of the local people [30-36]. A bottomland with $16 \mathrm{~km}^{2}$, which is adjacent to Qiangliang Lake district, was selected as our study field (Figure 1). The bottomland of Dongting Lake Region has an obvious characteristic that water arises in summer and land appears in winter. Rainfall pattern in the area is seasonal, with the heaviest rain falling from April to June and the lightest rain dropping from December to February. This kind of environment is quite suitable for snails to live and reproduce, meaning that Dongting Lake Region has provided optimal circumstances for S. japonica for a long time [37-41].

\section{Snail sampling}

Snail sampling was conducted from May 6th to May 10th in 2013 to obtain samples of snails in the bottomland of Dongting Lake Region. This bottomland area in Dongting Lake Region has a typical environment suitable for snail survival. Adopting systematic sampling methods, snail sampling was executed by 10 well-trained collectors working in the local station for schistosomiasis control for four days. We used tweezers and paper bags to collect the snails on the surface of bottomland. The horizontal and vertical distance between sampling points were both $20 \mathrm{~m}$, and the sampling area per point was about $0.11 \mathrm{~m}^{2}$. We selected 50 points in the horizontal direction, while also selecting 10 lines in the vertical direction. The total area of sampling site is $10,000 \mathrm{~m}^{2}$. In each collection, gathered snails were appropriately labeled and transported to the laboratory of the local station for schistosomiasis control.

After collection, snails were transported in flasks containing $5 \mathrm{ml}$ of clear, filtered water. After four hours, the numbers of dead and alive snails were counted. The 


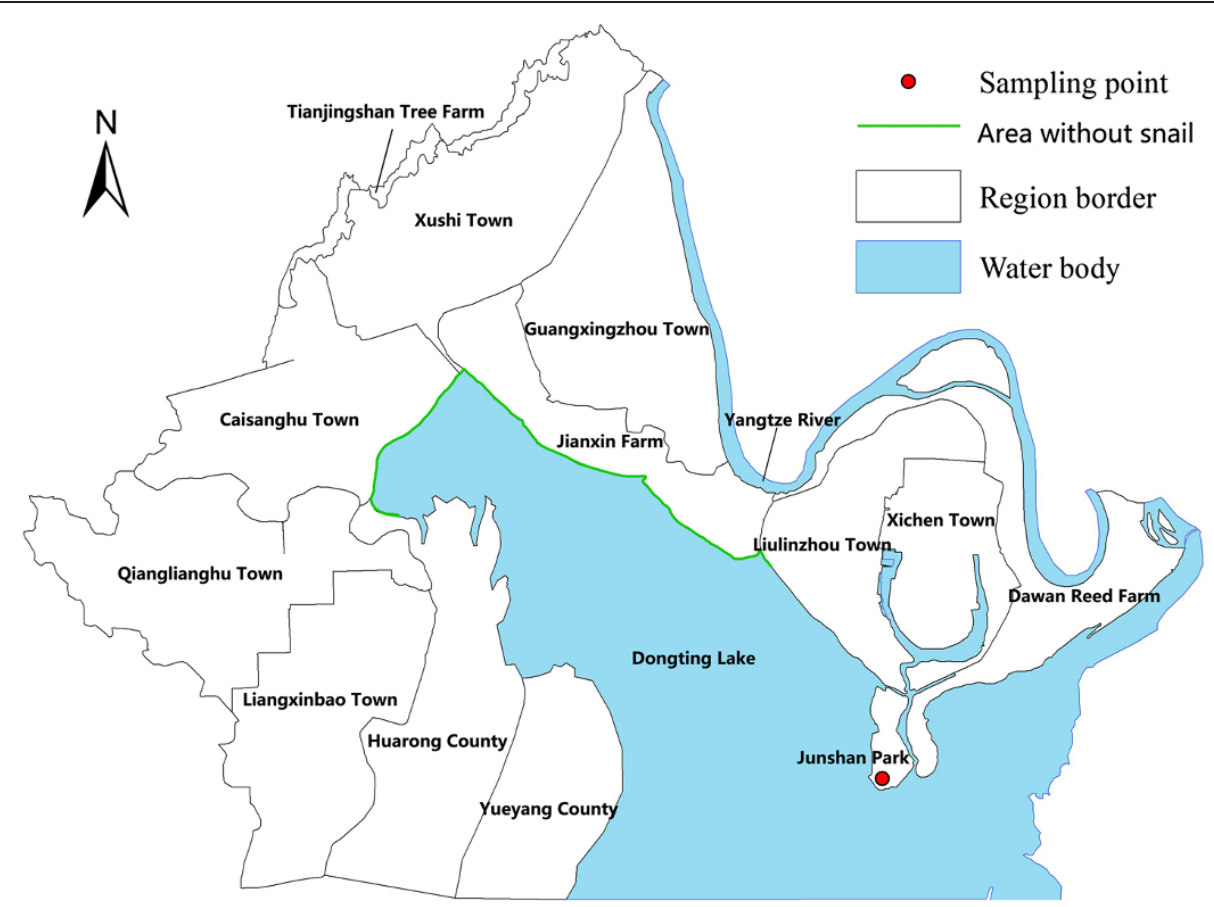

Figure 1 Location of sampled bottomland in Dongting Lake Region. Detailed legends: This map shows where the sampled bottomland is located in.

water in the flasks was used to make smears to examine for the existence of cercariae under a microscope. Snails were killed using niclosamide.

\section{Environmental factor sampling}

Sampling of environmental factors simultaneously coincided with snail sampling. While measuring environmental factors, the weather generally remained consistent, providing mostly sunny weather. Four elements including water content, $\mathrm{pH}$, elevation and temperature were collected using professional equipment containing a GPS handheld $\mathrm{PC}$, a moisture meter, and a $\mathrm{pH}$ meter (which can detect both $\mathrm{pH}$ and temperature). All these factors were gathered in the snail sampling points. Once recording was complete, these parameters were checked, and then matched with mean snail density.

Water content of soil was measured using a Soil Moisture Meter (SieldScout TDR 300, Spectrum Ltd, USA). The accuracy of this instrument was $\pm 3.0 \%$ volumetric water content. The probe of the moisture meter was put into soil $15 \mathrm{~cm}$ under the surface to detect the water content, and the data was recorded when the water content reading was steady. After the process of collecting the data, all the information would be exported into a computer. To make the data accurate, adjustment for soil moisture was needed. Thirty sampling points were randomly selected from the snail sampling points, to collect samples of soil weighing $30 \mathrm{~g}$ in $15 \mathrm{~cm}$ deep for soil moisture assessment. Soil samples were placed into a plastic container to prevent the change of properties in soil. The water content of these sampling soils was tested using the drying method [42]. Finally, a calibration curve was calculated, and all the information of water moisture corrected accordingly.

Temperature and $\mathrm{pH}$ of soil were measured with Portable Waterproof pH/ORP/C Meter (HANNA HI991002N, Hanna Instruments Ltd, Italy). The accuracy of this equipment was $\pm 1^{\circ} \mathrm{C}$ outside and $\pm 0.02 \mathrm{pH}$. The glass probe of the meter was put into soil $15 \mathrm{~cm}$ under the surface, and the data was recorded when the reading was steady. Before the next measurement, the glass probe was washed by distilled water. To obtain the $\mathrm{pH}$ value, we collected the $15 \mathrm{~cm}$ deep soil weighing $30 \mathrm{~g}$ (the number of soil sampling was 30) to put into a plastic container. The soil was dissolved by $25 \mathrm{ml}$ soil sample preparation solution (HANNA HI7051, Hanna Instruments Ltd, Italy). The $\mathrm{pH}$ meter was used to detect the soil suspension. From these recordings, calibration curve was calculated and data corrected.

Elevation was measured with GPS handheld PC (TRIMBLE GeoExplorer 3000 GeoXM Handheld, Trimble Navigation Ltd, USA). The accuracy of detecting elevation is $10 \mathrm{~cm}$ with an external antenna (Trimble Zephyr 2, Trimble Navigation Ltd, USA). This antenna offers precise positioning with sub-millimeter phase center accuracy and a robust low-elevation satellite tracking. Before the collection of elevation, the level of signals was at least six satellites. The elevation and 
geographic coordinate system information was automatically written into the meter after initiating the recording and keeping the device still for 15 seconds. The data was then exported into a computer to generate a map, using ArcGIS 10.0 (Environmental Systems Research Institute, Inc., Redlands, CA).

\section{Statistical analysis}

Using GeoDa 1.4.0 (Spatial Analysis Laboratory, University of Illinois, Urbana-Champaign, IL, USA, https://geodacenter.asu.edu/), we first calculated the univariate LISA indicator of snails to produce a LISA cluster map of the bottomland of Dongting Lake Region. In the procedure of calculation, we chose queen contiguity as the contiguity weight.

Spatial clustering of the snails was checked. The data yielded spatial clusters (positive autocorrelation) falling into two categories (High-High and Low-Low) and two classes of outliers (negative autocorrelation, High-Low and Low-High). Inference for all Moran's I statistics is based on permutation testing, where a reference distribution is calculated for spatial randomness and compared with the observed data over multiple iterations [43].

In the calculation of LISA, p values $<0.05$ were considered statistically significant. This was the unified test criterion in the following computations. The theory of this statistic is as follows:

\section{Local Indicators of Spatial Association, LISA}

The local autocorrelation statistics for each observation is defined as the following form: [29]

$$
I_{i}=Z_{i} \sum_{j} W_{i j} Z_{j}
$$

$Z_{i}$ and $Z_{j}$ are deviations from the mean, which are standardized $z$-scores for each variable i and $j$, respectively. The standardized Z-score for each variable is computed as the observed value (e.g., water content) at location i minus the mean rate for the neighbors $j$ (e.g., average water content) divided by the standard deviation. The summation over $j$ is such that only the neighboring values $j \in J$ are included. In this research, $I_{i}$ denotes the LISA index of per variable in point $i$ and $W_{i j}$ is the distancebased spatial weight matrix revealing the proximity of point $i$ to point $j$.

The clustering degree rises as LISA value increases. An area with high LISA value is a clustered area that should be noticed. There are four association patterns, including high-high, high-low, low-high and low-low. High-high and low-low patterns reveal that the value in one point is similar with that around it. High-low and low-high illustrates that value in one point has different neighboring values.
Second, we calculated univariate statistics and Moran's I statistic of each variable to check distribution and to measure spatial autocorrelation. Adopting GeoDa 1.4.0. Positive values of Moran's I statistic reveals that neighbouring points have similar values and vice versa. Spatial models are suitable for variables with significant spatial autocorrelation.

Third, since dependent value and mean snail density was not gaussian distributed, we used square root method to transform it. An ordinary least squares (OLS) regression model was fitted to estimate the association of environmental factors and mean snail density. This step was conducted in IBM SPSS 19.0 (IBM Corporation, USA). Colinearity was measured by computing variance inflation factor (VIF). Colinearity could be neglected if VIF is less than 10.

Owing to the existence of spatial autocorrelation, geographically weighted regression (GWR) more accurately analyzed the association between environmental factors and mean snail density. We used GWR 4.0 (Professor Tomoki Nakaya, The Department of Geography, Ritsumeikan University, Kyoto, Japan, http://www.st-andrews. ac.uk/geoinformatics/) to analyze the association. In the process of calculation, gaussian model and fixed gaussian kernel type were adopted. We chose an appropriate spatial weighting function based on AIC. The linear model and GWR model were compared. If the difference of AIC in these two models was more than three, GWR would be utilized as the better model, even considering the complicacy of GWR. The theory is as follows:

\section{Geographically weighted regression, GWR}

$Y_{i}$ denotes the dependent variable, $K$ represents the number of variables, $i$ is the number of samples; $\alpha_{0}$ is a primary parameter, $\varepsilon_{i}$ is the spatial error in point $i$, and the corresponding coefficient estimate is $=\left(X^{T} X\right)^{-1} X^{T} Y$. The function is as following:

$$
Y_{i}=\alpha_{0}\left(u_{i}, v_{i}\right)+\sum \alpha_{k}\left(u_{i}, v_{i}\right) k_{i k}+\varepsilon_{i}
$$

$\left(u_{i}, v_{i}\right)$ is the coordinate of central point. In this study, $Y_{i}$ is the mean snail density in point $i ; k_{i k}$ is $\mathrm{k}^{\text {th }}$ environmental factor in point $i$, where the subscript $k$ denotes the count of environmental elements; and $\varepsilon_{i}$ is the residual error. $\alpha_{k}\left(u_{i}, v_{i}\right)$ represents the value of continuous function $\alpha_{k}(u, v)$ in point $i$. In GWR [44], regression coefficient is not a global unified value, but a parameter that will change in different locations. These estimates based on geographical space describe how the parameter changes with the variation of space. Therefore, we can explore the spatial heterogeneity in these variables.

Fourth, values in the points possessing spatial clustering were extracted. Univariate statistics were displayed according to two groups (high-high and low-low). Similarly, 
we extracted significant points in the GWR model and analyzed univariate statistics in two groups (positive correlation and negative association).

Finally, interquartile ranges in these two tables of environmental factors were compared with the reported reference scopes suitable for snail habitation and reproduction.

\section{Results}

\section{Univariate analyses}

In this study, a total of 8,589 snail specimens were collected from 397 sampling sites. The range of snail density was 0 to 148 snails per $0.11 \mathrm{~m}^{2}$, and the mean value was 23.58 with a standard deviation of 24.82. After square root transformation, the range changed to be 0 to 12.17 , and the mean value became 5.79 with a standard deviation of 2.99. Therefore, the transformation made the dependent variable approach gaussian distribution.

The range of humidity was from $0.07 \%$ to $0.99 \%$, and the mean value of it was $0.67 \%$ with the standard deviation of $0.26 \%$; the average value of elevation was $27.97 \mathrm{~m}$ with the standard deviation of $6.11 \mathrm{~m}$ as its range was from 18.45 to $52.67 \mathrm{~m}$. The overall range of $\mathrm{pH}$ was from 5.23 to 8.70 with a mean value of 6.77 and the standard deviation of 0.37 ; the average value of temperature was $24.36^{\circ} \mathrm{C}$ with its range from 20.20 to $32.10^{\circ} \mathrm{C}$ and the STD of $1.80^{\circ} \mathrm{C}$.

Both the mean snail density and its transformed value had high spatial autocorrelation (both Moran's I values were 0.50 ), demonstrating that sampling points with high snail density tended to be located close to other similar high value points.

Besides the mean snail density, three environmental factors including water content, $\mathrm{pH}$ and temperature had high spatial autocorrelation. Elevation was much lower, but it was also spatially autocorrelated.

\section{Spatial distribution of snails}

Figure 2 shows the local spatial pattern of mean snail density. High-high and low-low locations were typically spatially clustered, while high-low and low-high locations are spatial outliers. It was worth noticing that LISA cluster map only refers to the core of the cluster. The cluster was classified as such when the value at a location is more similar to its neighbors than would be the case under spatial randomness. The clustering of high-high mean snail density was located in the middle region of the bottomland study area, while the clustering of low-low mean snail density was mainly situated at the margin of the bottomland (Figure 1).

\section{Multivariate analyses}

Table 1 presents the results of the full regression model. Since all the variance inflation factors of independent variables were below 10 , multicollinearity was not problematic. Among four parameters, water content and $\mathrm{pH}$ were statistically significant, showing a negative association with mean snail density. Elevation and temperature had no statistical significance.

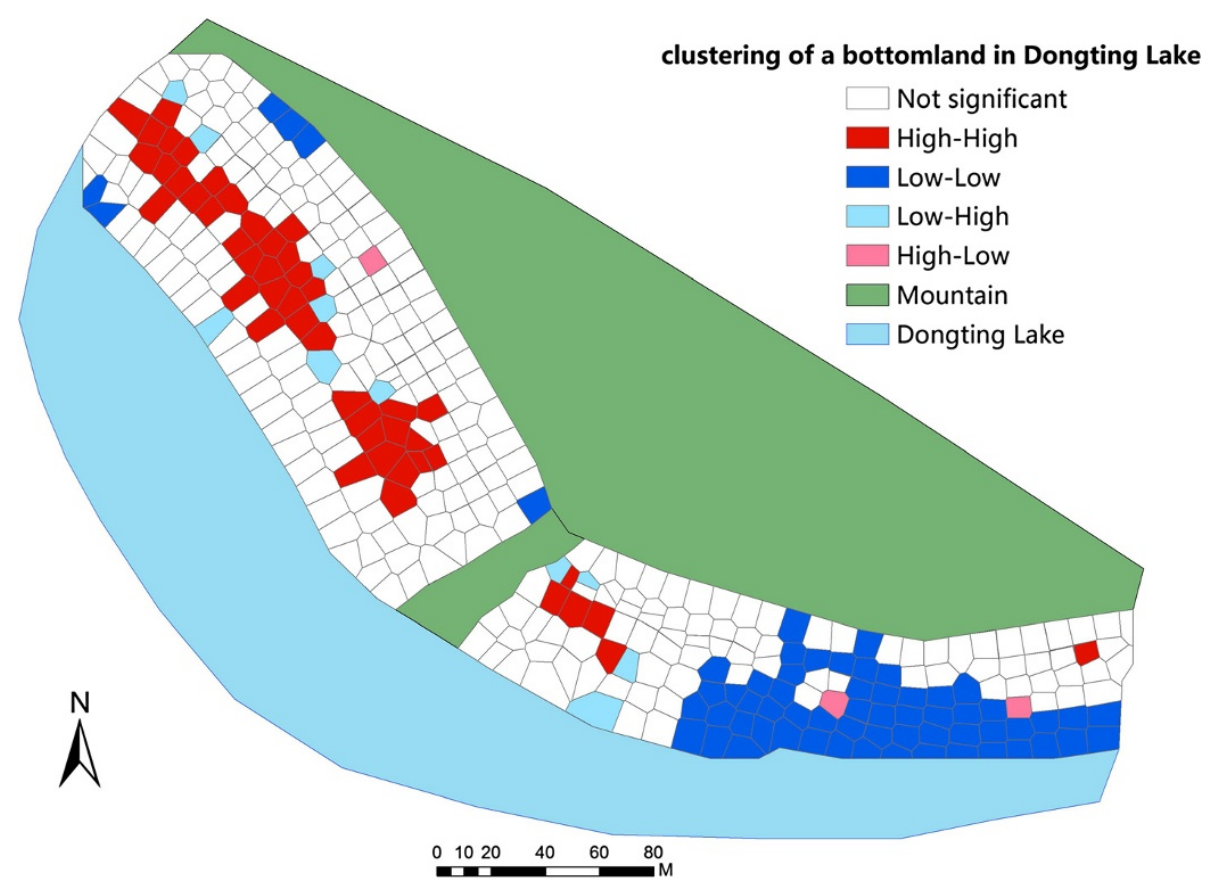

Figure 2 LISA cluster of mean snail density in a bottomland of Dongting Lake Region. Detailed legends: This map shows the spatial cluster locations. 
Table 1 OLS regression model: association between mean snail density and natural characteristics in Dongting Lake Region

\begin{tabular}{|c|c|c|c|c|c|c|}
\hline \multicolumn{7}{|l|}{ Model Fit } \\
\hline$R^{2}$ & \multicolumn{2}{|c|}{ Adjusted $\mathrm{R}^{2}$} & \multicolumn{2}{|c|}{ Log likelihood } & \multicolumn{2}{|l|}{$\mathrm{AIC}$} \\
\hline 0.14 & \multicolumn{2}{|l|}{0.13} & \multicolumn{2}{|c|}{-866.91} & \multicolumn{2}{|c|}{1743.82} \\
\hline \multicolumn{7}{|l|}{ Model Estimation } \\
\hline & VIF & $\beta$ & SD & $\mathrm{t}$ & $P$ & \\
\hline Constant & & 17.04 & 3.38 & 5.05 & 0.00 & $* *$ \\
\hline Water- content (\%) & 1.46 & -0.03 & 0.01 & -3.78 & 0.00 & $* *$ \\
\hline Elevation (m) & 1.16 & 0.02 & 0.03 & 0.75 & 0.45 & * \\
\hline $\mathrm{PH}$ & 1.45 & -1.30 & 0.48 & -2.72 & 0.01 & $* *$ \\
\hline Temperature $\left({ }^{\circ} \mathrm{C}\right)$ & 1.26 & -0.13 & 0.09 & -1.41 & 0.16 & * \\
\hline \multicolumn{7}{|l|}{ Diagnostic Tests } \\
\hline & \multicolumn{2}{|l|}{ Tests } & \multicolumn{2}{|l|}{ DF } & Value & $\mathrm{P}$ \\
\hline Normality of errors & \multicolumn{2}{|c|}{ Jarque-Bera } & \multicolumn{2}{|l|}{2} & 0.03 & 0.99 \\
\hline \multirow[t]{3}{*}{ Heteroskedasticity } & \multicolumn{2}{|c|}{ Breusch-Pagan } & \multicolumn{2}{|l|}{4} & 12.97 & 0.01 \\
\hline & \multicolumn{2}{|c|}{ Koenker-Bassett } & \multicolumn{2}{|l|}{4} & 21.06 & 0.00 \\
\hline & \multicolumn{2}{|c|}{ White } & \multicolumn{2}{|l|}{14} & 54.99 & 0.00 \\
\hline Spatial dependence & \multicolumn{2}{|c|}{ Moran'sl(error) } & \multicolumn{2}{|l|}{0.48} & 14.79 & 0.00 \\
\hline
\end{tabular}

**P $<0.05,{ }^{*} \mathrm{P}>0.05$.

The fit of the OLS model was not good (Log likelihood $=-8$, AIC $=1743.82$, Adjusted $\left.R^{2}=0.13\right)$. The high probabilities of the Jarque-Bera score indicated gaussian distribution of the error. Low probabilities of White test, Breusch-Pagan and Koenker-Bassett scores showed the existence of heteroskedasticity $(\mathrm{P}<0.05)$. Moran's I (error) score was positive and highly significant $(\mathrm{P}<0.05)$, indicating a strong positive spatial autocorrelation of the residuals.

As the dependent variable and independent variables were spatially autocorrelated and locally distributed, we used geographically weighted regression (GWR) to analyze the association between them. In the GWR model, every sampling point would produce a specified model containing coefficients and its p-value. Compared with OLS model, the regression coefficients changed considerably. Environmental factors had both negative association and positive association with the square root of mean snail density, as different sampling points had varying local conditions. At the same time, the significance of the four covariates also changed.

Table 2 reveals the results of the GWR model. Contrasting the model fit part in OLS and GWR models, it was certain that GWR performed better. In the diagnostic assessment of GWR, the results demonstrated that GWR was better than global spatial regression models. The low possibility of GWR ANOVA test reported that GWR had some improvements. The significant F statistic resulting from the ANOVA test was utilized to establish
Table 2 GWR models: association between mean snail density and natural characteristics in Dongting Lake region Model Fit

$R^{2} \quad$ Adjusted $R^{2} \quad$ Log likelihood AIC

$\begin{array}{llll}0.74 & 0.65 & 1305.35 & 1446.73\end{array}$

Model Estimation

\begin{tabular}{llllllllll}
\multicolumn{1}{c}{} & $\beta$ & \multicolumn{1}{c}{$\mathrm{t}$} \\
& Min & Max & Mean & STD & Min & Max & Mean & STD \\
Constant & 2.14 & 7.28 & 5.11 & 1.32 & 2.80 & 19.60 & 11.65 & 3.64 \\
Water- content & -5.45 & 3.18 & -0.61 & 2.10 & -8.07 & 6.44 & -0.94 & 4.30 \\
$(\%)$ & & & & & & & & \\
Elevation(m) & -1.89 & 1.16 & -0.02 & 0.49 & -4.23 & 2.62 & 0.02 & 1.22 \\
PH & -2.02 & 0.86 & -0.17 & 0.59 & -3.55 & 2.45 & -0.20 & 1.17 \\
Temperature $\left({ }^{\circ} \mathrm{C}\right)$ & -1.52 & 0.72 & -0.10 & 0.42 & -3.86 & 2.10 & -0.21 & 0.99 \\
Diagnostic Tests & & & & & & & & \\
GWR Anova Table & & & & & & & & \\
& SS & DF & MS & & F & & P \\
Global Residuals & 2717.14 & 5.00 & & & & & \\
GWR & 1901.67 & 88.27 & 21.54 & & & \\
Improvement & & & & & & & \\
GWR Residuals & 815.48 & 262.73 & 3.10 & & 6.94 & & $<0.05$
\end{tabular}

Geographical variability tests of local coefficients

\begin{tabular}{llll} 
& $F$ & DOF for $F$ test & $\begin{array}{l}\text { DIFF of } \\
\text { Criterion }\end{array}$ \\
Constant & 4.19 & 2.83 & -8.61 \\
Water content & 7.39 & 3.20 & -25.92 \\
Elevation & 5.77 & 3.28 & -12.03 \\
$\mathrm{PH}$ & 6.84 & 3.31 & -15.74 \\
Temperature & 279.51 & 3.07 & -388.96 \\
\hline
\end{tabular}

whether the GWR model provides a better fit over the global regression model, and these values support the use of GWR. The DIFF of Criterion was the result of a test of spatial variability in a variable's coefficient (based on an AIC criterion). DIFF of four independent variables had negative values, indicating that GWR was better than global analysis. DOF was the degree of freedom in the ANOVA analysis.Collectively, GWR was established as a good performing model for these variables.

To further illustrate the coefficients and the relevant P-value in GWR model, GWR parameter maps of each covariate were constructed. In the northwestern part of the studied bottomland, the GWR map of water content (Figure 3) indicated that, the mean snail density was positively associated with water content when the range of the coefficient was from 1.50 to 3.78 . The map illustrated that an increase of water content might generate an increase in mean snail density in a certain area. Meanwhile, it suggested that the relationship between water content and snails was positive but not linear. 


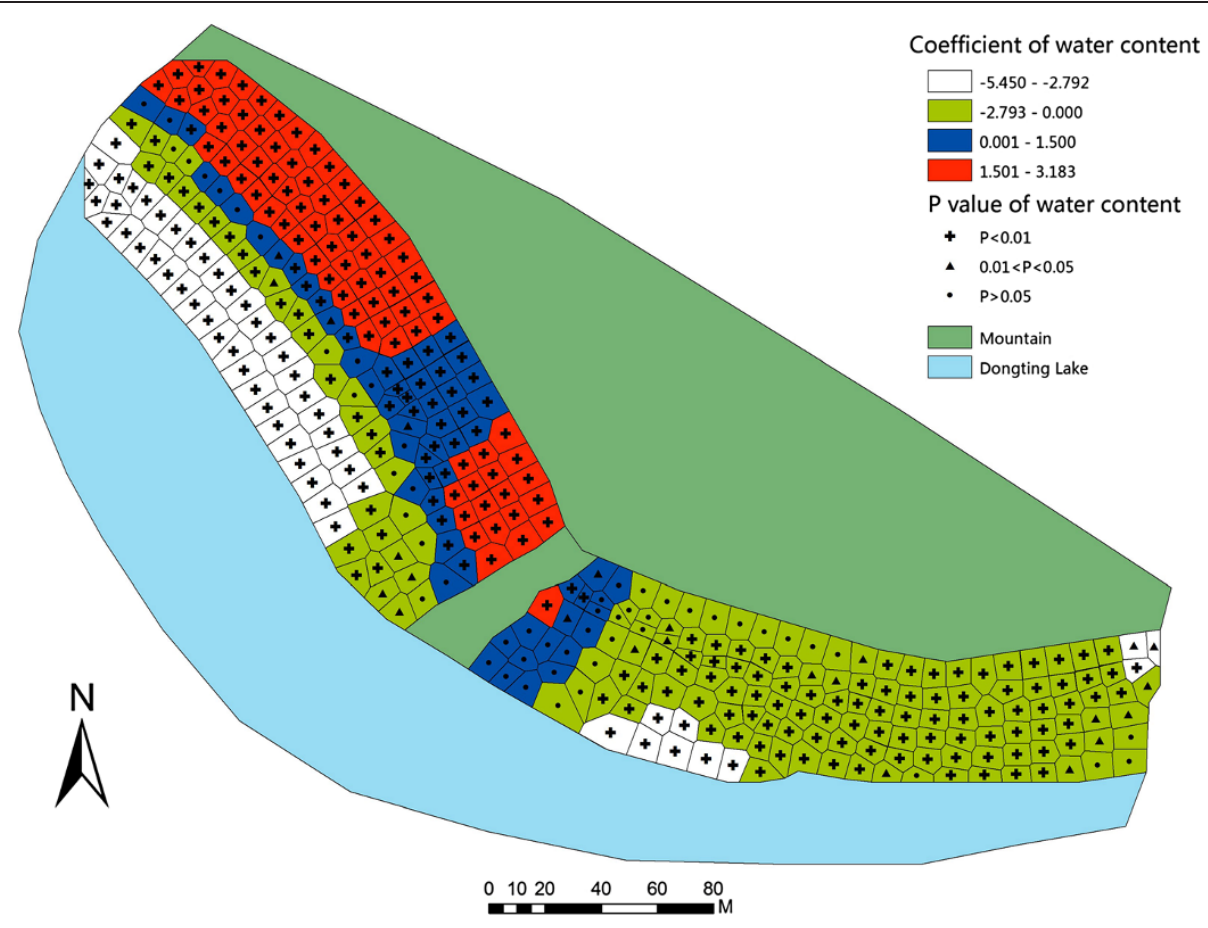

Figure 3 Coefficient and significance of water content in GWR model. Detailed legends: This map shows the value of parameters and its significance in GWR model to illustrate how water content influences mean snail density.

Three other factors had statistically significant positive associations with mean snail density in the areas. The ranges of coefficients were from 0.42 to 0.86 (pH, Figure 4), from 0.35 to 0.72 (temperature, Figure 5), and from 0.57 to 1.16 (elevation, Figure 6).

\section{Suitable range analyses}

According to the results of the LISA cluster analysis, snail habitats were divided into high-high clustered areas and low-low clustered areas. Therefore, as illustrated in Table 3, four environmental factors were divided into high-high and low-low groups respectively. Since all the factors did not follow gaussian distribution, inter-quartile range was a better parameter to illustrate a hospitable range for snail survival.

The inter-quartile range of high-high clustered area in water content was from $58.70 \%$ to $58.93 \%$, suggesting that snails would survive and reproduce largely in that region. Similarly, the interquartile range of the low-low clustered area was from $70.00 \%$ to $99.90 \%$. The low-low clustered area indicated that snails would not thrive in this area.

For inter-quartile range of elevation, the scope of high-high clustered area was from $23.50 \mathrm{~m}$ to $30.39 \mathrm{~m}$, while the range of low-low clustered area was from $25.97 \mathrm{~m}$ to $34.60 \mathrm{~m}$. For inter-quartile range of $\mathrm{pH}$, the range of high-high clustered area was from 6.56 to 6.85, as the scope of low-low clustered area was from 6.93 to
7.20. For temperature, the range of high-high clustered area was from $22.73^{\circ} \mathrm{C}$ to $24.28^{\circ} \mathrm{C}$, while the scope of low-low clustered area was from $25.10^{\circ} \mathrm{C}$ to $25.83^{\circ} \mathrm{C}$.

Table 4 presents that water content is positively associated with mean snail density when the water content is between $36.58 \%$ and $61.08 \%$. However, this relationship was negatively associated when within the range of $66.60 \%$ to $99.90 \%$. Similarly, elevation and mean snail density had positive correlation when elevation range was from $24.79 \mathrm{~m}$ to $29.44 \mathrm{~m}$, and they had negative correlation when elevation range was from $21.85 \mathrm{~m}$ to $25.25 \mathrm{~m}$. PH and mean snail density were positively correlated in $\mathrm{pH}$ range from 6.54 to 6.89 , but were negatively correlated in $\mathrm{pH}$ range from 6.73 to 7.05 . Temperature and mean snail density had positive association as temperature scope was from $24.30^{\circ} \mathrm{C}$ to $25.70^{\circ} \mathrm{C}$, while the negative scope was from $22.40^{\circ} \mathrm{C}$ to $24.15^{\circ} \mathrm{C}$.

\section{Discussion}

Oncomelania hupensis is the unique intermediate host of $S$. japonica in China, and its distribution is highly consistent with the $S$. japonica epidemic area [45]. The survival, reproduction and spread of these snails are often influenced by many factors, and among these elements, environmental factors (i.e. climate, hydrology, vegetation, and sunlight) play a significant role [46]. In many past studies, the effects of these factors on snails have alone 


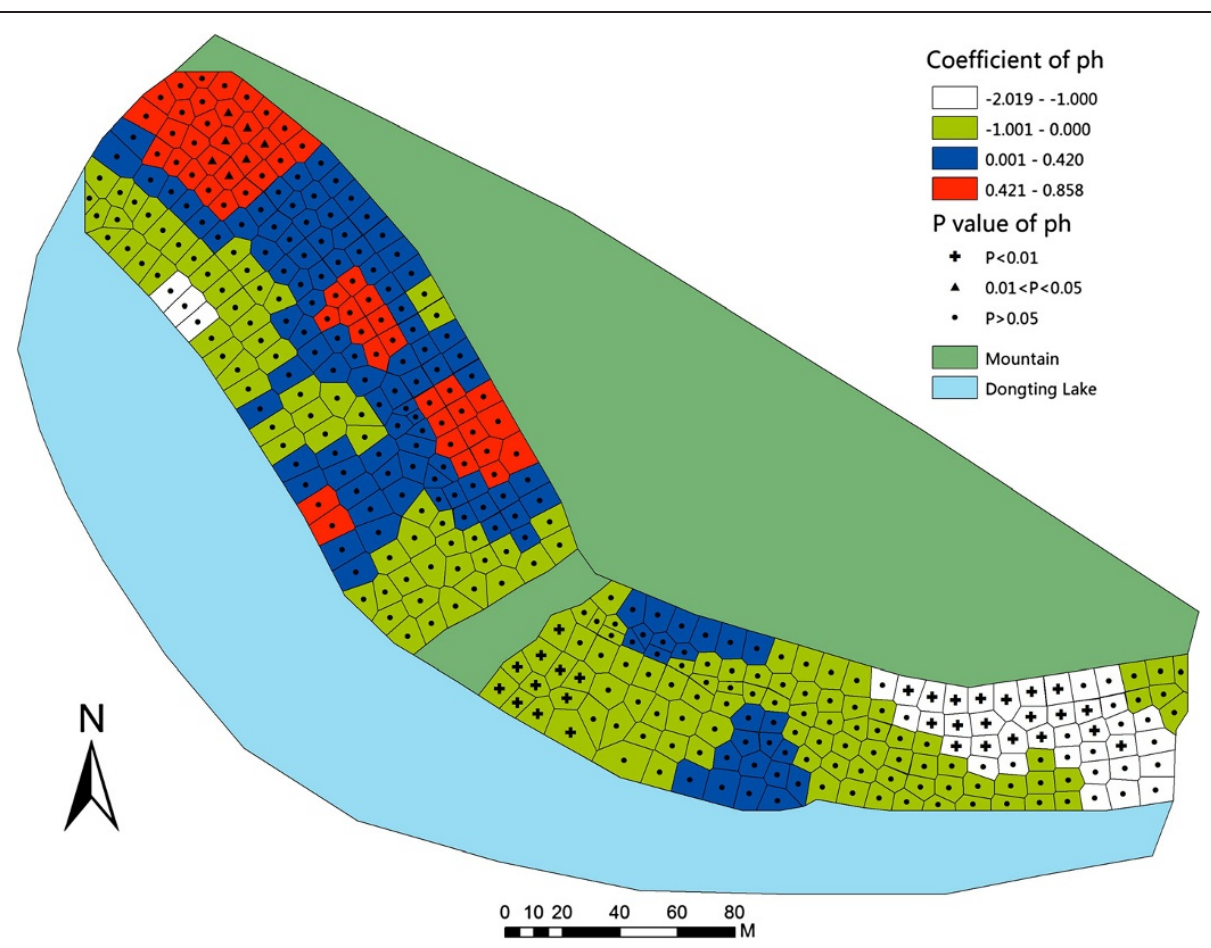

Figure 4 Coefficient and significance of $\mathrm{pH}$ in GWR model. Detailed legends: This map shows the value of parameters and its significance in GWR model to illustrate how pH influences mean snail density.

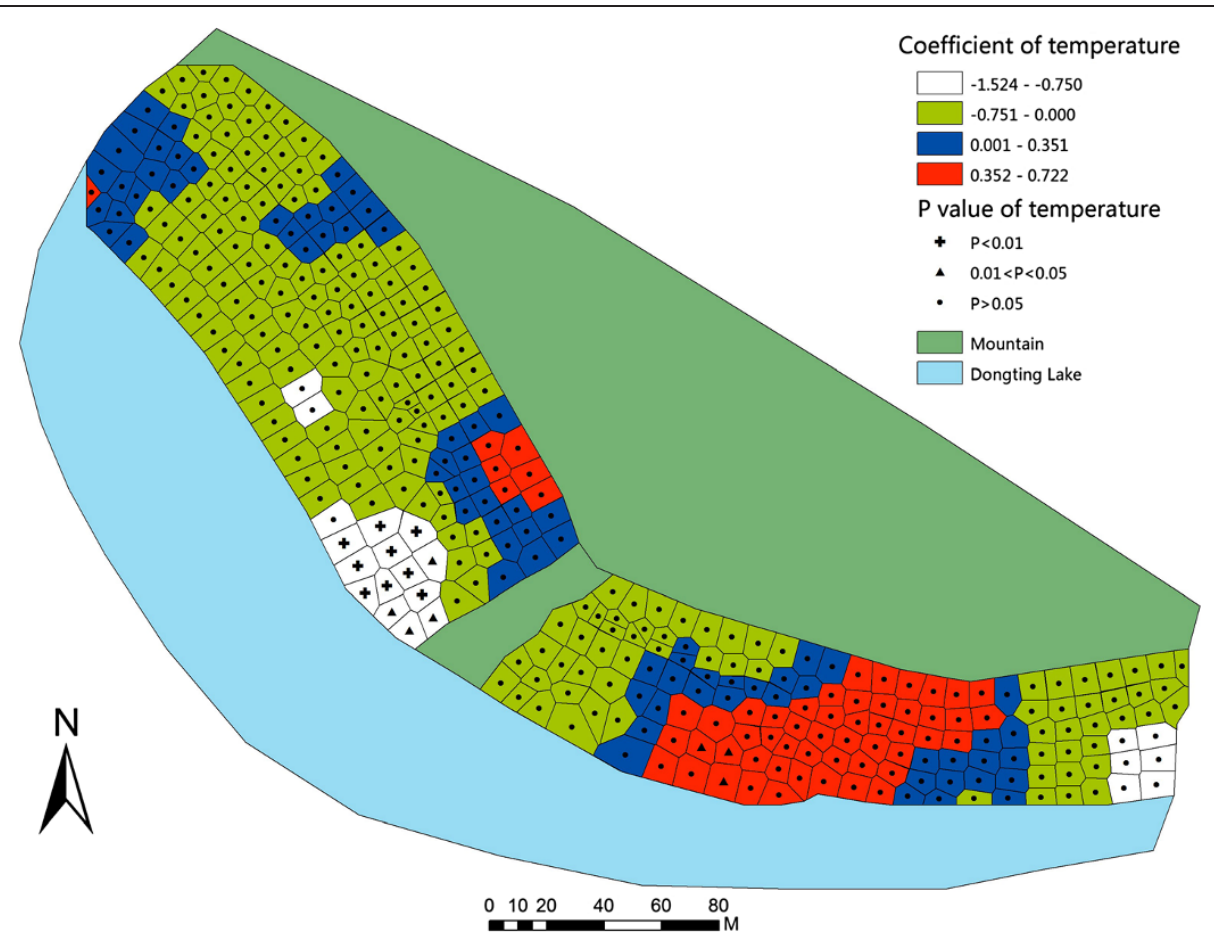

Figure 5 Coefficient and significance of temperature in GWR model. Detailed legends: This map shows the value of parameters and its significance in GWR model to illustrate how temperature influences mean snail density. 


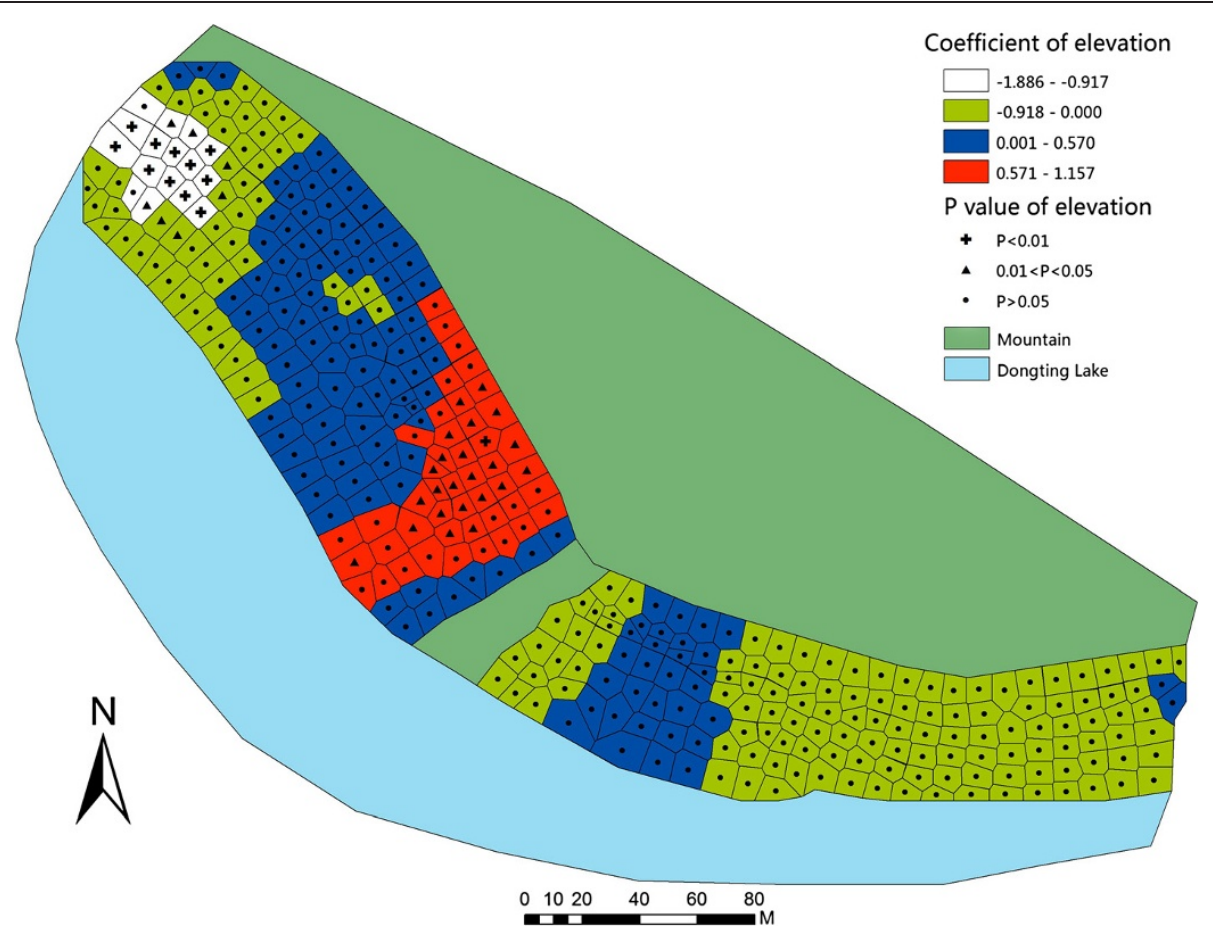

Figure 6 Coefficient and significance of elevation in GWR model. Detailed legends: This map shows the value of parameters and its significance in GWR model to illustrate how elevation influences mean snail density.

been analyzed in a laboratory setting [46-50] or a field $[51,52]$. However, these factors have interactions so that occasional synergetic effects can be generated [53]. Hence, we detected the four main environmental factors (i.e. water content, $\mathrm{pH}$, temperature of soil and elevation) in the bottomland of Dongting Lake Region, and included these four elements, into the spatial model to analyze the complex collective effects of the elements on snails. Our results showed that snails had obvious spatial clustering areas in the bottomland (high-high clustering areas are located in the northwestern bottomland, while low-low clustering areas are located in the southeastern bottomland). This finding of the spatial cluster of snails was

Table 3 Univariate statistics of the independent variables of four clusters in Dongting Lake Region

\begin{tabular}{llllll}
\hline & & $\mathbf{N}$ & Median & $\begin{array}{l}\text { Percentiles } \\
\mathbf{( 2 5 \% )}\end{array}$ & $\begin{array}{l}\text { Percentiles } \\
\mathbf{( 7 5 \% )}\end{array}$ \\
\hline Water content (\%) & High-High & 44 & 65.90 & 58.70 & 68.93 \\
& Low-Low & 54 & 99.90 & 99.90 & 99.90 \\
Elevation(m) & High-High & 44 & 26.66 & 23.50 & 30.39 \\
& Low-Low & 54 & 27.87 & 25.97 & 34.60 \\
$\mathrm{PH}$ & High-High & 44 & 6.65 & 6.56 & 6.85 \\
& Low-Low & 54 & 7.05 & 6.93 & 7.20 \\
Temperature $\left({ }^{\circ} \mathrm{C}\right)$ & High-High & 44 & 23.50 & 22.73 & 24.28 \\
& Low-Low & 54 & 25.40 & 25.10 & 25.83 \\
\hline
\end{tabular}

consistent with previous reports [54,55]. Based on this finding, the ranges of the environmental factors in these high-high clustered areas of snails might be the suitable ranges for these snails, while the scopes of circumstance elements in the low-low clustered areas possibly generate unsuitable ranges for snails. According to this hypothesis, we discussed the possible optimum scopes. Meanwhile, we used the GWR model to analyze the association between snails and environmental factors, so we could provide an alternative means of identifying the possible optimum ranges for the snails.

The results of this study showed that the range of $58.70 \%$ to $68.93 \%$ was the moisture content scope in the

Table 4 Univariate statistics of the independent variables of linear correlation in GWR in Dongting Lake Region

\begin{tabular}{llllll}
\hline & & N & Median & $\begin{array}{l}\text { Percentiles } \\
(\mathbf{2 5 \% )}\end{array}$ & $\begin{array}{l}\text { Percentiles } \\
\mathbf{( 7 5 \% )}\end{array}$ \\
\hline Water content (\%) & positive & 118 & 52.30 & 36.58 & 61.08 \\
& negative & 185 & 79.20 & 66.60 & 99.90 \\
Elevation(m) & positive & 24 & 27.60 & 24.79 & 29.44 \\
& negative & 18 & 24.12 & 21.85 & 25.25 \\
$\mathrm{PH}$ & positive & 7 & 6.69 & 6.54 & 6.89 \\
& negative & 30 & 6.93 & 6.73 & 7.05 \\
Temperature $\left({ }^{\circ} \mathrm{C}\right)$ & positive & 4 & 25.00 & 24.30 & 25.70 \\
& negative & 13 & 23.60 & 22.40 & 24.15 \\
\hline
\end{tabular}


high-high clustered areas of snails, while in the low-low clustered areas, most of the water content values were 99.90\%, with some values being below $30.00 \%$. Therefore, snails might not survive when water content of soil is more than $99.90 \%$ or less than $30.00 \%$. This indicated that mean snail density and moisture content had a U-shaped association, thus snails would live and breed in this given water range. Snails might start to migrate out of their habitat if water content was out of this suitable scope. Chen et al. [56] reported that a small number of snails began to move when water content was more than $12.00 \%$, about one fifth snails would start moving at $20.00 \%$ water content, about half of snails would move at $30.00 \%$ water content, and the snails would be very active at $40.00 \%$ water content. However, when water content was more than $80.00 \%$, mean snail density would decline [56]. Similarly, the association in GWR model showed that the mean snail density increased gradually when the water scope was between 36.58 and $61.08 \%$, while they decreased gradually as the range was from 66.60 to $99.90 \%$. These further supported our previous results. Considering the outcomes of past and current experiments, we supposed that $58.70 \%$ to $68.93 \%$ might be a suitable range of water moisture in soil for the snails in our study site.

In the high-high clustered areas of snails, the elevation was from $23.50 \mathrm{~m}$ to $30.39 \mathrm{~m}$, while in the low-low clustered regions, the elevation was from $25.97 \mathrm{~m}$ to $34.60 \mathrm{~m}$. These two kinds of clustered ranges of elevation had some interactions, and it might be related to only the elevation considered and other factors may not be involved. When the four factors were analyzed together in the GWR model, our results showed that the mean snail density increased gradually when the elevation was from $24.79 \mathrm{~m}$ to $29.44 \mathrm{~m}$, while the mean snail density decreased gradually when the elevation was from $25.25 \mathrm{~m}$ to $21.85 \mathrm{~m}$. Previously reported ranges from studies being conducted in eastern Dongting Lake Region include optimal elevations of $24.50 \mathrm{~m}$ to $26.00 \mathrm{~m}$ in Dongkou [51] and $25.00 \mathrm{~m}$ to $27.50 \mathrm{~m}$ in Matang [52]. Based on the results of the previous literature and this study,
$23.5 \mathrm{~m}$ to $26.0 \mathrm{~m}$ might be an optimum scope of the elevation for snails in our study field.

The results of $\mathrm{pH}$ showed that high-high clustered range was from 6.56 to 6.85 , and low-low clustered range was between 6.93 and 7.20. The ranges of high-high clustered and low-low clustered were both in the range 6.7 to 7.8, as reported in Table 5. The results of GWR model highlighted that the mean snail density increased gradually when the $\mathrm{pH}$ was between 6.54 and 6.89 , while mean snail density decreased gradually when the $\mathrm{pH}$ was from 6.73 to 7.05. Based on the results of the previous reports and this study, 6.6 to 7.0 might be a suitable range of $\mathrm{pH}$ for snails in this study field.

The high-high clustered range of temperature was from $22.73^{\circ} \mathrm{C}$ to $24.28^{\circ} \mathrm{C}$, as the low-low clustered scope of that was from $25.10^{\circ} \mathrm{C}$ to $25.83^{\circ} \mathrm{C}$. Su et al. (1963) reported that snail survival would be threatened if the temperature was less than $5.00^{\circ} \mathrm{C}$ or more than $35.00^{\circ} \mathrm{C}$, and the snail would not eat food past those parameters [58]. The results of the GWR model presented show that the mean snail density increased gradually when the temperature was between $24.30^{\circ} \mathrm{C}$ and $25.70^{\circ} \mathrm{C}$, while mean snail density decreased gradually when the temperature was from $24.15^{\circ} \mathrm{C}$ to $22.40^{\circ} \mathrm{C}$. Considering the results in this study and previous studies, a possible suitable range of temperature was from $22.73^{\circ} \mathrm{C}$ to $24.23^{\circ} \mathrm{C}$ in our study site. It is worth noting that uncertainty existed in the process of model fitting.

The optimum temperature range in this study presented a narrower range in comparison to prior literature. This difference might be attributed to a new method applied during our study. In contrast to previous research, information of environmental factors was collected in our study sites, whereas data of environmental elements were gathered in laboratories among previous studies. The data was then analyzed by local indicators of spatial autocorrelation and spatial regression model, which took the spatial attributes into account. In previous literature, descriptive methods and linear models were commonly adopted. However, some limitations may exist with these past

Table 5 Reported ranges of four environmental factors suitable for snail existence

\begin{tabular}{|c|c|c|c|c|c|}
\hline \multirow[t]{2}{*}{ Author/date } & \multirow[t]{2}{*}{ Method } & \multicolumn{4}{|c|}{ Referenc range } \\
\hline & & Water-content(\%) & Temperature $\left({ }^{\circ} \mathrm{C}\right)$ & $\mathrm{PH}$ & Elevaton $(\mathrm{m})$ \\
\hline OuYang et al. 2009 [57] & Survey & - & $13 \sim 25$ & - & - \\
\hline Xu et al. 2001 [49] & Experiment & 40 & $20 \sim 30$ & - & - \\
\hline Wang et al. 2007 [47] & Experiment & - & $20 \sim 30$ & - & - \\
\hline Hu et al. 2010 [52] & Survey & - & - & - & $25.0 \sim 27.5$ \\
\hline Lu et al. 2013 [48] & Experiment & - & $20 \sim 25$ & - & - \\
\hline Luo et al. 2012 [51] & Survey & - & - & - & $24.5 \sim 26.0$ \\
\hline Yang et al. 2009 [46] & Experiment & 30 & $20 \sim 26$ & $6.7 \sim 7.8$ & - \\
\hline Zhou et al. 2005 [50] & Experiment & - & $20 \sim 25$ & $6.8 \sim 7.5$ & - \\
\hline
\end{tabular}


approaches. First, experimental data might not reflect the real situation in the sampling sites, since the delivery of samples and microenvironment in a laboratory might change the content in the samples. Second, descriptive methods and linear model did not consider the spatial clustering in snails in the process of analysis.

Several limitations were highlighted in our study. First, the sampling of snails and environmental elements were conducted only in summer. Further studies could be carried out during spring in the same positions. Second, our study was mainly carried out in bottomland and water. The sampling sites could be expanded in future research.

\section{Conclusion}

In summary, this research conducted a field survey, collected data in the sampling sites and analyzed the data using spatial techniques. Compared with previous reports, the explorations in this study adopted field research instead of experimental and used a new method to analyze data. Natural factors of the soil might decide snail survival, and the relationship between mean snail density and natural factors (e.g., moisture content) was nonlinear. Indeed, it follows a U-shaped curve as the snails do not seem to survive when the soil water content is either extremely high $(99.9 \%)$ or less than $30 \%$, leading to snail dispersion outside the optimal range of 59\%-69\%. These findings might contribute to better prediction and control of snail habitat dynamics, leading to more accurate prevention of S. japonica transmission.

\section{Competing interests}

All authors declare that they have no competing interests.

\section{Authors' contributions}

YZ, GR and QJ conceived the study; JW, YZ, GR, LL, SZ, XS, ZH, BC, JY, and QJ performed the field collections; JW, SL, AC and $Y Z$ wrote the manuscript; JW performed statistical analyses. All the authors read and approved the final version of the manuscript.

\section{Acknowledgements}

This work is supported by National Natural Science Foundation of China (No. 30590374), the National S \& T Major Program (Grant No. 2012ZX10004-220 and 2008ZX10004-011), and Shanghai Leading Academic Discipline Project (Project No. B118).

\section{Author details}

${ }^{1}$ Department of Epidemiology, School of Public Health, Fudan University, 138 Yi Xue Yuan Road, Shanghai 200032, China. ${ }^{2}$ Key Laboratory of Public Health Safety, Ministry of Education, Fudan University, 138 Yi Xue Yuan Road, Shanghai 200032, China. ${ }^{3}$ Center for Tropical Disease Research, Fudan University, 138 Yi Xue Yuan Road, Shanghai 200032, China. ${ }^{4}$ Department of Environmental and Global Health, College of Public Health and Health Professions, University of Florida, Gainesville, FL, USA. ${ }^{5}$ Emerging Pathogens Institute, University of Florida, Gainesville, FL, USA. ${ }^{6}$ Department of Epidemiology, College of Public Health and Health Professions, University of Florida, Gainesville, FL, USA. ${ }^{7}$ Hunan station for Schistosomiasis Control, Changsha, Hunan Province 410000, China. ${ }^{8}$ Junshan office of Leading Group for Schistosomiasis Control, Yueyang, Hunan province 414000, China. 9 Junshan station for Schistosomiasis Control, Yueyang, Hunan Province 414000, China. ${ }^{10}$ Qianlianghu station for Schistosomiasis Control, Yueyang, Hunan Province 414000, China.
Received: 3 January 2014 Accepted: 1 May 2014

Published: 9 May 2014

\section{References}

1. Schistosomiasis-A major public health problem. http://www.who.int/ schistosomiasis/en/.

2. Zhou YB, Liang S, Jiang QW: Factors impacting on progress towards elimination of transmission of schistosomiasis japonica in China. Parasit Vectors 2012, 5:275.

3. Hu Y, Zhang ZJ, Chen Y, Wang Z, Gao J, Tao B, Jiang QW: Spatial pattern of schistosomiasis in Xingzi, Jiangxi Province, China: the effects of environmental factors. Parasit Vectors 2013, 6:214

4. Lin DD, Wu XH, Jiang QW, Lin JJ, Zhou XN: Strategic empHasis for research development of schistosomiasis control in China. Chin J Schisto Contro 2009, 21:1-5. in Chinese.

5. Zhou XN, Jiang QW, Wang TP, Lin DD, Wu XH: Status and strategy for research development of schistosomiasis control in China. Chin J Schisto Contro 2005, 17:1-3. in Chinese.

6. Zhou YB, Zheng HM, Jiang QW: A diagnostic challenge for Schistosomiasis japonica in China: consequences on praziquantel-based morbidity control. Parasit Vectors 2011, 4:194.

7. Zhou XN, Jiang QW, Guo JG, Lin DD, Zhu R, Yang GJ, Yang K, Li SZ, Xu J: Road map for transmission interruption of schistosomiasis in China. Chin J Schisto Contro 2012, 24:1-4. in Chinese.

8. Ma W, Liao WG, Kuang SF, Liu JJ, Lian YX: Study on response of suitable environmental for oncomelania breeding grouds to variation of flow regime. J Yang Riv Sci Rese Inst 2010, 27:65-69. in Chinese.

9. Guo D, Zhang Y, Zeng D, Wang H, Li X, Li Y, Fan X: Functional properties of hemocyanin from Oncomelania hupensis, the intermediate host of Schistosoma japonicum. Exp Parasitol 2009, 123:277-281. in Chinese.

10. Wu XH, Xu XJ, Xiao BZ, Wang RB, Dai YH, Xu J, Wu CG, Wei HF, Zhou XN, Zheng J: Study on the risk factors of schistosomiasis transmission in the Three Gorges Reservoir Areaslllnfluence of the socioeconomic development on schistosomiasis transmission. Chin J Schisto Contro 2007, 19:183-187. in Chinese.

11. Liang YS, Wang W, Li HJ, Tao YH, Xu YL, Shen XH, Huang YX, Dai JR: Impact of factors related to pattern of water diversion of South to North Water Diversion Project on spread north of Oncomelania snails. Chin J Schisto Contro 2009, 21:280-284. in Chinese.

12. Zhou X, Sun L, Jiang Q, Guo J, Wang T, Lin D, Yang G, Hong Q, Huang T, Zhang S, Wang Q, Hu F, Guo J: GeograpHic information systems spatial analysis on transmission of schistosomiasis in China. Chin J Schisto Contro 2000, 21:261-313. in Chinese.

13. Li LH, Zhou YB, Yao BD, Wu JY, Zheng SB, Song XX, He Z, You JB, Cai B, Zhao GM, Jiang QW: Natural growth and decline of Oncomelania hupensis snails in marshland of Qianliang Lake district in Eastern Dongting Lake area, China. Chin J Schisto Contro 2013, 25:383-386. in Chinese.

14. Zhang ZJ, Peng WX, Jiang QW: Application progress of Spatial analysis in the research of schistosomiasis. J Trop Dis Parasitol 2005, 3:243-249. in Chinese.

15. Zhao F, Zhu R, Zhang LJ, Zhang ZJ, Li YP, He MZ, Zhou YB, Guo JG, Zhao GM, Jiang QW: Application of satscan in detection of schistosomiasis clusters in marshland and lake areas. Chin J Schisto Contro 2011, 23:28-31. in Chinese.

16. Dijkstra A, Janssen F, de Bakker M, Bos J, Lub R, van Wissen LJ, Hak E: Using spatial analysis to predict health care use at the local level: a case study of type 2 diabetes medication use and its association with demograpHic change and socioeconomic status. PLoS One 2013, 8:e72730.

17. Chen DR, Wen TH: Elucidating the changing socio-spatial dynamics of neighborhood effects on adult obesity risk in Taiwan from 2001 to 2005. Health Place 2010, 16:1248-1258.

18. Weidmann C, Schneider S, Litaker D, Weck E, Kluter H: A spatial regression analysis of German community characteristics associated with voluntary non-remunerated blood donor rates. Vox Sang 2012, 102:47-54.

19. Sun LP, Liang YS, Wu HH, Tian ZX, Dai JR, Yang K, Hong QB, Zhou XN, Yang GJ: A Google Earth-based surveillance system for schistosomiasis japonica implemented in the lower reaches of the Yangtze River, China. Parasit Vectors 2011, 4:223.

20. Owusu-Edusei KJ, Chesson HW: Using spatial regression methods to examine the association between county-level racial/ethnic composition and reported cases of Chlamydia and gonorrhea: an illustration with data from the state of Texas. Sex Transm Dis 2009, 36:657-664. 
21. Yu D, Peterson NA, Sheffer MA, Reid RJ, Schnieder JE: Tobacco outlet density and demograpHics: analysing the relationships with a spatial regression approach. Public Health 2010, 124:412-416

22. Paciorek CJ: The importance of scale for spatial-confounding bias and precision of spatial regression estimators. Stat Sci 2010, 25:107-125.

23. Perez SI, Diniz-Filho JA, Bernal V, Gonzalez PN: Spatial regression techniques for inter-population data: studying the relationships between morpHological and environmental variation. J Evol Bio/ 2010, 23:237-248,

24. Cakmak S, Burnett RT, Jerrett M, Goldberg MS, Pope CARD, Ma R, Gultekin T, Thun M, Krewski D: Spatial regression models for large-cohort studies linking community air pollution and health. J Toxico Environ Health $A$ 2003, 66:1811-1823.

25. Yang $X Y$, Jin W: GIS-based spatial regression and prediction of water quality in river networks: a case study in lowa. J Environ Manage 2010, 91:1943-1951.

26. Duncan DT, Piras G, Dunn EC, Johnson RM, Melly SJ, Molnar BE: The built environmental and depressive symptoms among urban youth: A spatial regression study. Spat Spatio Epi 2013, 5:11-25.

27. Liu YX, Liu YX, Zhang BB, Zhang HM, Xue FZ: Spatial epidemiology study on tuberculosis based on geograpHical weighted regression. Chin $J$ Antituberc 2013, 35:343-346. in Chinese.

28. Chen BW, Xu BY, Ni ZZ, Li DY: The application of geograpHicalweighted models to Prevalence of endemic goiter. Appli Stat Man 2005, 24:113-117. in Chinese.

29. Anselin L: Local Indicators of Spatial Association-LISA. Geo Analysis 1995, 2:93-115.

30. Liu CZ, He HB, Wang ZX, Yu L, Guo FY, Xia M, Deng HJ, Li YS: Effect of marshland isolation and grazing prohibition on schistosomiasis control in Dongting Lake region. Chin J Schisto Contro 2010, 22:459-463. in Chinese.

31. Wang HY, He Z, Zhou YB, Wang W, Li JX, Zhang ZJ, Peng WX, Jiang QW: Observation on the living status of Oncomelania hupensis in Dongting Lake Area. Fudan Uni J Medi Sci 2010, 37:430-433. in Chinese.

32. He HB: Thought of schistosomiasis control strategy with empHasis on controlling sources of infection in lake and marshland endemic regions. Chin J Schisto Contro 2011, 23:710-713. in Chinese.

33. Chen SY, Xie WP, Zhou P, Tian B: Effect evaluation on comprehensive measures with empHasis on infection source for schistomiasis control. J Trop Dis Parasitol 2008, 6:20-21. in Chinese.

34. Chen JB, Tang GX, Xia MY, Xu GX, Wang JM: Effect of measures laying empHasis on schistosomiasis infection source control. Parasitos Infec Dis 2008, 6:84-85. in Chinese.

35. Gao LR, Zheng MH, Zhang B, Liu WB, Zhao XR, Zhang QH: Declining polychlorinated dibenzo-p-dioxins and dibenzofurans levels in the sediments from Dongting Lake in China. Chemosphere 2008, 73:176-179.

36. Li YS, Raso G, Zhao ZY, He YK, Ellis MK, McManus DP: Large water management projects and schistosomiasis control, dongting lake region, china. Emerg Infect Dis 2007, 13:973-979.

37. He MZ, Peng WX, Zhou YB, Yi HWL, Liu GM, Jiang QW: Application of Landsat TM images on the snail habitats monitoring in mountainous regions. Fudan Uni J Medi Sci 2010, 35:510-513. in Chinese.

38. Li YP, Li LH, He MZ, Zhao F, He Z, Wan W, Li JX, Jiang J, Zhou YB, Jiang QW: Snail habitats detection in the marshland of Eastern Dongting Lake Area, based on China-Brazil Earth Resources Satellite-02B CCD data. Chin J Schisto Contro 2011, 32:583-586. in Chinese.

39. Li YP, He Z, He MZ, Jiang J, Li JX, Zhou YB, Zhang ZJ, Jiang QW: Impact of the changing water level on the variance of Oncomelania hupensis populations in Lake Area with general additive model. Chin J Schisto Contro 2010, 31:1148-1154. in Chinese.

40. Yao BD, Zhou YB, Wang ZL, Tian AP, Zhu SP, Wei CJ, Yang QY, Lu BK, Liao YZ, $H u$ BJ, Yi P, Jiang QW: Study on spatial-temporal variation of infected snail in bottomland areas after an integrated control strategy at village level in the marshland and lake regions based on geograpHic information system Chi J Epi 2012, 33:702-705. in Chinese.

41. Yao BD, Wang ZL, Zhang ZJ, Tian AP, Zhu SP, Hu BJ GFH, Wang QZ, Yi P, Jiang QW: Application of multi-temporal china-Brazil earth recourses satemte-02 data on survemance of dynamic changes of water body of rivers and oncomelania snail habitats in anxiang county. Chin J Schisto Contro 2012, 24:160-163. + 167, in Chinese.

42. Li Y, Wang D: Comparative study on different detemination methods of soil moisture. J Anhui Agri 2010, 38:9110-9112. in Chinese.
43. Highfield L: Spatial patterns of breast cancer incidence and uninsured women of MammograpHy screening Age. Breast J 2013, 19:293-301.

44. Nakaya T, Fotheringham AS, Brusdon X, Charlton M: GeograpHically weighted Poisson regression for disease association mapping. Stat Med 2005, 24:2695-2717.

45. Zhou YB, Yang MX, Zhao GM, Wei JG, Jiang QW: Oncomelania hupensis (Gastropoda: Rissooidea), Intermediate host of schistosoma japonicum in China: Genetics and molecular phylogeny based amplified fragment length polymorphisms. Malacologia 2007, 49:367-382.

46. Yang $P$, Dong XQ: The Effect of Ecological factors of snail research and ecological snail control in the prevention and control of schistosomiasis. End Dis Bull 2009, 24:52-53. + 55, in Chinese.

47. Wang JS, Lu JY, Wei GY, Yao SM: Impact of environmental changes on oncomelania spread. J Yang Riv Sci Rese Inst 2007, 24:16-19. in Chinese.

48. Lu LL, Wang DL: Research progress on the distribution of cercariae and snail in dongting lake areas. J Jiaying Uni 2013, 31:63-66. in Chinese.

49. Xu YM, Zhang SQ: The influence of environmental factors on snail growth and distribution. Int J Medi Parasit Dis 2011, 38:218-222. in Chinese.

50. Zhou XN, Zhang Y, Hong QB, Xu JD, Wang TP: Science on Oncomelania Snail. Beijing, China: Sci Press; 2005:9-19. in Chinese.

51. Luo ZH, Wei WY, Li ZJ, Ding L, Yuan LP, Xia M, Tang L, Ren GH, Wang JS, Wei GY: Impact of environmental changes on Oncomelania snail distribution in Dongting Lake beach. Chin J Schisto Contro 2012, 24:387-392. in Chinese.

52. Hu G, Zhuo SJ, Huang CL, Yi P, Liu T, Zhan YS: Effect of gradient and regetation on distribution of schistosome infectedOncomelaniasnails in Dongting Lakemarshland. Chin J Schisto Contro 2010, 22:136-140. in Chinese.

53. Li ZJ, Chen HG, Liu YM, Zeng XJ, Lin DD, Wan WH: Studies on relationship between vegetation and snail distribution inside and outside embankment of Poyang Lake region. Chin J Schisto Contro 2006, 18:406-410. in Chinese.

54. Zhang ZJ, Peng WX, Zhou YB, Zhuang JL, Jiang QW, Chen GX, Cui DY: Spatial autocorrelation analysis of the small-scale distribution of Oncomelania hupensis in marshland and lake regions. Chin J Schisto Contro 2007, 19:418-423. in Chinese.

55. Zhou YB, Song L, Chen GX, Rea C, Han SM, He ZG, Li YP, Wei JG, Zhao GM, Jiang QW: Spatial-temporal variations of Schistosoma japonicum distribution after an integrated national control strategy: a cohort in a marshland area of China. BMC Public Health 2013, 13:297.

56. Chen LY, Xu XJ, Yang XX, LV GY: Impact on snail ecology by soil humidity and temperature in Jianghan plain after the Three Georges Dam project. Chin J Schisto Contro 2002, 14:258-260. in Chinese.

57. OuYang $H$, OuYang FF, Feng $H$ : The inherent principle research of Meteorological elements and schistosomiasis breeding. 26th Ann Meet Chi Mete Soc Venue Clim Cha Hum Heal Hangz Zhej Chi 2009, 9: in Chinese. 58. Zhou XN: Science on Oncomelania Snail. Science Press 2005, 9: in Chinese

\section{doi:10.1186/1756-3305-7-216}

Cite this article as: Wu et al:: Identification of optimum scopes of environmental factors for snails using spatial analysis techniques in Dongting Lake Region, China. Parasites \& Vectors 2014 7:216.

\section{Submit your next manuscript to BioMed Central and take full advantage of:}

- Convenient online submission

- Thorough peer review

- No space constraints or color figure charges

- Immediate publication on acceptance

- Inclusion in PubMed, CAS, Scopus and Google Scholar

- Research which is freely available for redistribution 